\title{
INVESTIGATIONS ON LOW HEAT REJECTION DIESEL ENGINE WITH CARBURETED ALCOHOLS AND CRUDE COTTONSEED OIL
}

\author{
Y. Nagini and M.V.S. Murali Krishna* \\ Mechanical Engineering Department, Chaitanya Bharathi Institute of Technology, \\ Gandipet, Hyderabad, Telangana, India \\ *Corresponding Author
}

\begin{abstract}
Alcohols and vegetable oils are promising fuels for replacing conventional diesel fuel. The advantages of alcohol (more volatility, low carbon to hydrogen ratio) and vegetable oils (comparable calorific value and cetane number) are attracting features to use them as substituted fuels in diesel engines. However demerits of alcohol (low calorific value and low cetane number (measure of combustion quality in diesel engines)) and vegetable oils (high viscosity and low volatility) call for low heat rejection (LHR) engine which has high heat release rate and faster rate of combustion. Heat flow to the coolant is minimized by providing thermal insulation in the path of heat flow to the coolant. Investigations were carried out to study the exhaust emissions from high grade low heat rejection $(L H R)$ diesel engine consisting of air gap insulated piston with 3-mm air gap with superni (an alloy of nickel) crown, air gap insulated liner with superni insert and ceramic coated cylinder head with normal temperature condition of crude cottonseed oil and carbureted alcohol (methanol/butanol) with varied injection pressure and compared with methanol operation over butanol operation and also with net diesel operation on conventional engine $(C E)$. Exhaust emissions of particulate matter and oxides of nitrogen $\left(N O_{x}\right)$ were recorded by AVL Smoke meter and Netel Chromatograph $N_{x}$ analyzer respectively at full load operation of the engine. Aldehydes were measured by dinitrophenyl hydrazine (DNPH) method at full load operation of the engine. Particulate levels and $N O_{x}$ levels decreased by $92 \%$ and $12 \%$ respectively with LHR engine at recommended injection timing of $27^{\circ}$ bTDC (before top dead centre) and at an injection pressure of 190 bar with methanol operation in comparison with neat diesel operation on CE.
\end{abstract}

Keywords: Crude Vegetable Oil, Methanol, butanol, CE, LHR engine, Emissions.

Cite this Article: N Y. Nagini and M.V.S. Murali Krishna, Investigations on Low Heat Rejection Diesel Engine with Carbureted Alcohols and Crude Cotton Seed Oil, International Journal of Mechanical Engineering and Technology (IJMET), 12(5), 2021, pp. 19-30.

https://iaeme.com/Home/issue/IJMET?Volume=12\&Issue=5 


\section{INTRODUCTION}

Following fuel crisis and vehicular population growth, search for renewable and alternate fuels has become pertinent for the engine manufacturers, users and researchers involved in the combustion research. Vegetable oils, which are renewable have properties compatible to diesel fuels. Hence these fuels (straight vegetable oils, SVO) can be directly substituted in diesel engines without the modification of the engine. However, higher viscosity and chemical composition of unprocessed vegetable oils and fats have been shown [1] to cause problems in a number of areas (i) piston ring sticking; (ii) injector and combustion chamber deposits; (iii) fuel system deposits; (iv) reduced power; (v) reduced fuel economy and (vi) increased exhaust emissions due to high value of $\mathrm{C} / \mathrm{H}$ ratio $(\mathrm{C}=$ Number of carbon atoms, $\mathrm{H}=$ Number of hydrogen atoms in fuel composition).

Rudolph Diesel, the inventor of the diesel engine that bears his name, experimented with fuels ranging from powdered coal to peanut oil. [2]. Several researchers experimented the use of vegetable oils as fuel on conventional engines (CE) and reported that the performance was poor, citing the above mentioned problems of high viscosity, low volatility and their polyunsaturated character. Bio-diesels derived from vegetable oils present a very promising alternative to diesel fuel since biodiesels have numerous advantages compared to fossil fuels as they are renewable, biodegradable, provide energy security and foreign exchange savings besides addressing environmental concerns and socio-economic issues.[3-7]. Experiments were carried out with bio-diesel on $\mathrm{CE}$ and reported performance was comparable with pure diesel operation on CE.[8-12].

On the other hand alcohols are renewable and volatile fuels. There are many methods of inducting alcohols in diesel engines, out of which carburetion technique is simple one. Alcohol was inducted through a variable jet carburetor, installed in inlet manifold and diesel was injected in conventional manner. Investigations were carried out with carbureted alcohol and diesel on $\mathrm{CE}$ and reported that exhaust emissions of particulate matter and $\mathrm{NO}_{\mathrm{x}}$ decreased in comparison with pure diesel operation on CE. [13-16]. However, alcohols have low cetane number (quality of combustion in diesel engine). Hence engine modification was necessary if alcohol was used as fuel in diesel engine. The drawbacks of the crude vegetable oil, biodiesel and alcohol call for hot combustion chamber provided by LHR diesel engine.

The major concept of LHR engine is to reduce heat loss to the coolant, by providing thermal insulation in the path of heat flow to the coolant. LHR engines were classified depending on degree of insulation, such as low grade, medium grade and high grade engines. In low grade LHR engines, ceramic coatings were provided on piston, liner and cylinder head while in medium grade LHR engines, air gap was created in the piston and other components with lowthermal conductivity materials like superni, cast iron and mild steel etc. High grade LHR engines were the combination of low grade and medium grade.

Investigations were carried out by various researchers on low grade LHR ceramic coated diesel engines with pure diesel operation and reported that pollution levels of smoke decreased by $15 \%$ with ceramic coated engine. [17-19]. Experiments were carried out with biodiesel in low grade LHR diesel engine and reported that there was reduction of particulate matter and increase of $\mathrm{NO}_{\mathrm{x}}$ levels. [20-23].

Creating an air gap in the piston involved the complications of joining two different metals like bolted and welded design adopted by researchers in fixing the crown of the piston to the body of the piston could not withstand more than 78 hours. [24]. Later it was a successful attempt of screwing the crown made of low thermal conductivity material, nimonic (an alloy of nickel) to the body of the piston, by keeping a gasket, made of nimonic, in between these two parts. [25].It was reported from these investigations that smoke levels decreased by $12 \%$ at advanced injection timing of $29.5^{\circ} \mathrm{bTDC}$. 
Experiments were conducted on medium grade LHR engine which consisted of air gap insulated piston with superni crown and air gap insulated liner with superni insert with advanced injection timings and increased injection pressure with vegetable oils. [26-28]. They reported that particulate matter decreased by $20 \%$ and NOx levels increased by $45 \%$ at peak load operation with LHR engine.

Experiments were carried out with high grade LHR engine, which consisted of air gap insulated piston, air gap insulated liner and ceramic coated cylinder head with vegetable oils [29-31]. They reported that LHR engine further increased NOx levels and decreased smoke levels.

Alcohols, both ethanol and methanol were used in medium grade LHR engine along with vegetable oil [32-34]. They reported that particulate matter and $\mathrm{NO}_{\mathrm{x}}$ emissions decreased considerably with LHR engine due to effect of higher heat generated in the combustion space due to adiabatic conditions improved alcohol combustion with varying pilot quantities of diesel. Vegetable oils have cetane number comparable with diesel fuel, but they have high viscosity and low volatility. Alcohols have low cetane fuels, though they have got high volatility. In order to take advantage from high cetane number and high volatility, both vegetable oils and alcohols can be used in LHR engine.

Particulate matter and $\mathrm{NO}_{\mathrm{x}}$ are the emissions from diesel engine cause [35-37] health hazards like inhaling of these pollutants cause severe headache, asthma, bronchitis, emphysema, lung cancer, nausea, slowing down of reflexes, vomiting sensation, respiratory problems, skin cancer, hemorrhage, dizziness, drowsiness, etc. The contaminated air containing carbon dioxide released from automobiles reaches ocean in the form of acid rain, there by polluting water. Hence control of these emissions is an immediate task and important.

As mentioned earlier, straight vegetable oil (SVO) cannot be used in diesel engines. Hence along with SVO, alcohol, which is volatile, was used in experiment. The present paper attempted to study exhaust emissions from high grade LHR engine, which contained air gap piston, air gap liner and ceramic coated cylinder head with crude cottonseed oil (CSO) with carbureted alcohol (methanol/ butanol) with varied injection pressure and compared with methanol operation with butanol operation on both versions of the engine and also with neat diesel operation on $\mathrm{CE}$ at $27^{\circ} \mathrm{bTDC}$ and at an injection pressure of $190 \mathrm{bar}$.

\section{METHODOLGY}

Figure 1 shows the assembly details of air gap insulated piston, air gap insulated liner and ceramic coated cylinder head. LHR diesel engine contained a two-part piston; the top crown made of low thermal conductivity material, superni- 90 screwed to aluminum body of the piston, providing a $3 \mathrm{~mm}$-air gap in between the crown and the body of the piston. The optimum thickness of air gap in the air gap piston was found to be 3-mm for improved performance of the engine with superni insert with diesel as fuel. [27]. A superni-90 insert was screwed to the top portion of the liner in such a manner that an air gap of 3-mm was maintained between the insert and the liner body. At $500^{\circ} \mathrm{C}$ the thermal conductivities of superni-90 and air are 20.92 and $0.057 \mathrm{~W} / \mathrm{m}-\mathrm{K}$ respectively. Partially stabilized zirconium (PSZ) of thickness 500 microns was coated by means of plasma coating technique.

The experimental setup used for the investigations of LHR diesel engine with cottonseed oil and carbureted alcohol is shown in Figure 1. CE had an aluminum alloy piston with a bore of $80 \mathrm{~mm}$ and a stroke of $110 \mathrm{~mm}$. The rated output of the engine was $3.68 \mathrm{~kW}$ at a speed of $1500 \mathrm{rpm}$. 


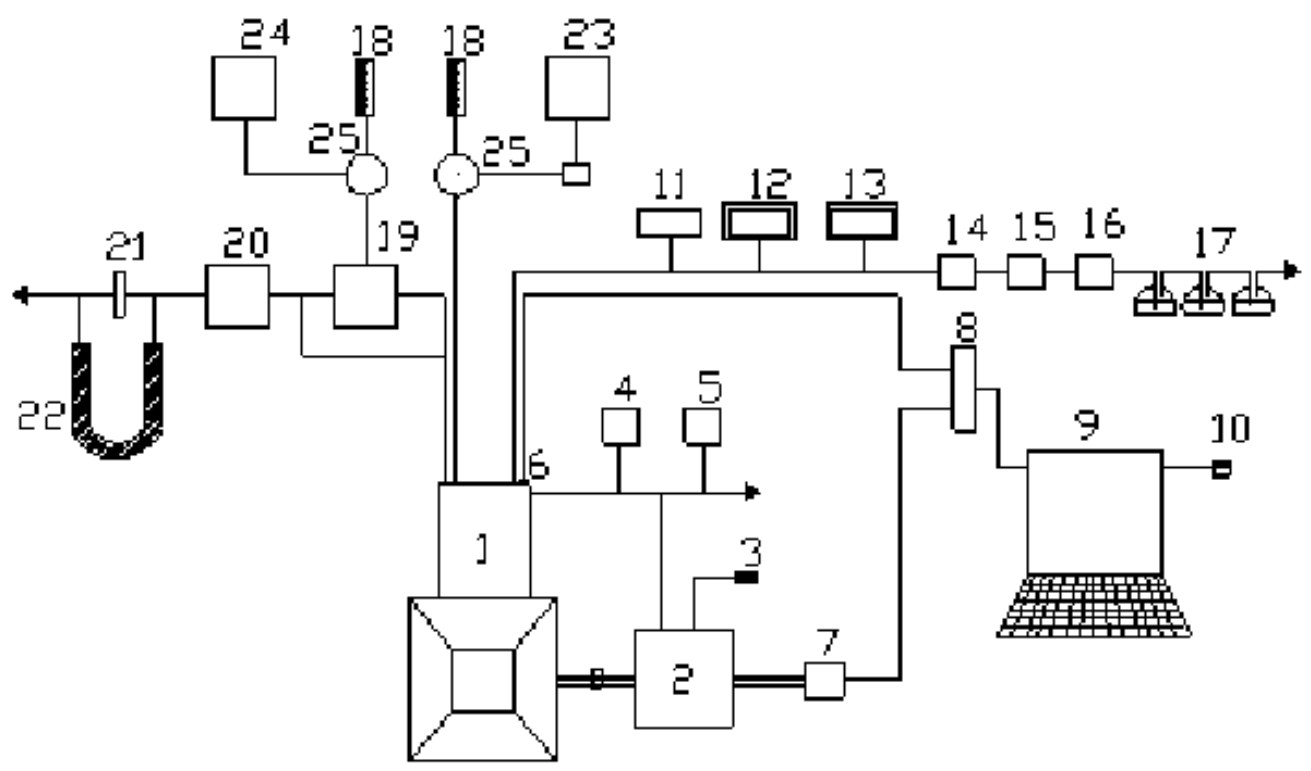

1.Engine, 2.Electical Dynamo meter, 3.Load Box, 4. Outlet jacket water temperature indicator, 5.Outlet-jacket water flow meter Orifice meter, 6. Piezo-electric pressure transducer, 7. TDC encoder 8.Console, 9. Pentium Personal Computer, 10. Printer, 11.Exhaust gas temperature indicator, 12.AVL Smoke meter, 13. Netel Chromatograph NOx Analyzer, 14. Filter, 15.Rotometer, 16. Hetaer,17. Round bottom flask containing DNPH solution, 18.Burette, 19. Variable jet carburetor, 20. Air box, 21.Orifice meter, 22. U-tube water manometer, 23.Dieesl tank/vegetable oil tank, 24.Alcohol tank, 25. Three-way valve.

Figure 2 The Experimental Set-up

The compression ratio was $16: 1$ and manufacturer's recommended injection timing and injection pressures were $27^{\circ} \mathrm{bTDC}$ and 190 bar respectively. The fuel injector had 3 holes of size $0.25 \mathrm{~mm}$. The combustion chamber consisted of a direct injection type with no special arrangement for swirling motion of air. The engine was connected to electric dynamometer for measuring its brake power. Alcohol was inducted through the variable carburetor jet, located at the inlet manifold of the engine at different percentages of diesel flow rate by mass basis and crude vegetable oil (CSO) was injected in conventional manner. Two separate fuel tanks and burette arrangements were made for measuring vegetable oil and alcohol consumptions. Airconsumption of the engine was measured by air-box method. The naturally aspirated engine was provided with water-cooling system in which inlet temperature of water was maintained at $80^{\circ} \mathrm{C}$ by adjusting the water flow rate. The engine oil was provided with a pressure feed system. No temperature control was incorporated, for measuring the lube oil temperature. Copper shims of suitable size were provided in between the pump body and the engine frame, to vary the injection timing and its effect on the performance of the engine was studied, along with the change of injection pressures from 190 bar to 270 bar (in steps of 40 bar) using nozzle testing device. The maximum injection pressure was restricted to 270 bar due to practical difficulties involved. Exhaust emissions of particulate matter and $\mathrm{NO}_{\mathrm{x}}$ were recorded by AVL smoke meter and Netel Chromatograph NOx analyzer respectively at various values of BMEP. With alcoholvegetable mixture operation, the major pollutant emitted from the engine is aldehydes. These aldehydes are carcinogenic in nature, which are harmful to human beings. The measure of the aldehydes is not sufficiently reported in the literature. DNPH method was employed for measuring aldehydes in the experiment. [32]. The exhaust of the engine was bubbled through 2,4 dinitrophenyl hydrazine (2,4 DNPH) solution. The hydrazones formed were extracted into chloroform and were analyzed by employing high performance liquid chromatography (HPLC) to find the percentage concentration of formaldehyde and acetaldehyde in the exhaust of the engine. 
India with just $2.4 \%$ of the global area supports more than $16 \%$ of world's human population and $17 \%$ of the cattle population. According to economic survey (2010-2011), of the cultivable land area, about 250 million hectares are classified as waste and degraded or marginal land. If the non-forest waste-lands could be used to cultivate plants which can survive on such soil and which can produce oilseeds, these could be effectively used to combat fuels shortage in the country and at the same time bring such degrade lands back to its productive capacity. India is the second largest country to produce cottonseed oil. The whole seeds can be crushed to yield about $25 \%$ oil. Double crushing can increase the yield to $28.5 \%$ and solvent extraction to $30 \%$. The properties of the diesel, vegetable oil, ethanol and methanol used in this work are presented in Table-1.

Table 1 Properties of test fuels

\begin{tabular}{|l|c|c|c|c|}
\hline \multicolumn{1}{|c|}{ Test Fuel } & $\begin{array}{c}\text { Viscosity at } \\
\mathbf{2 5}^{\mathbf{0}} \mathbf{C} \\
(\mathbf{C e n t i - p o i s e )}\end{array}$ & $\begin{array}{c}\text { Density at } \\
\mathbf{2 5}^{\circ} \mathbf{C}\end{array}$ & Cetane number & $\begin{array}{c}\text { Calorific value } \\
\mathbf{( k J / k g )}\end{array}$ \\
\hline Diesel & 12.5 & 0.84 & 55 & 42000 \\
\hline Crude cottonseed oil (CSO) & 125 & 0.90 & 45 & 40000 \\
\hline Methanol & -- & 0.79 & 06 & 19700 \\
\hline Butanol & -- & 0.72 & 09 & 36700 \\
\hline
\end{tabular}

\section{RESULTS AND DISCUSSION}

\subsection{Performance Parameters}

Investigations were carried out with the objective of determining the factors that would allow maximum use of alcohol in diesel engine with best possible efficiency at all loads.

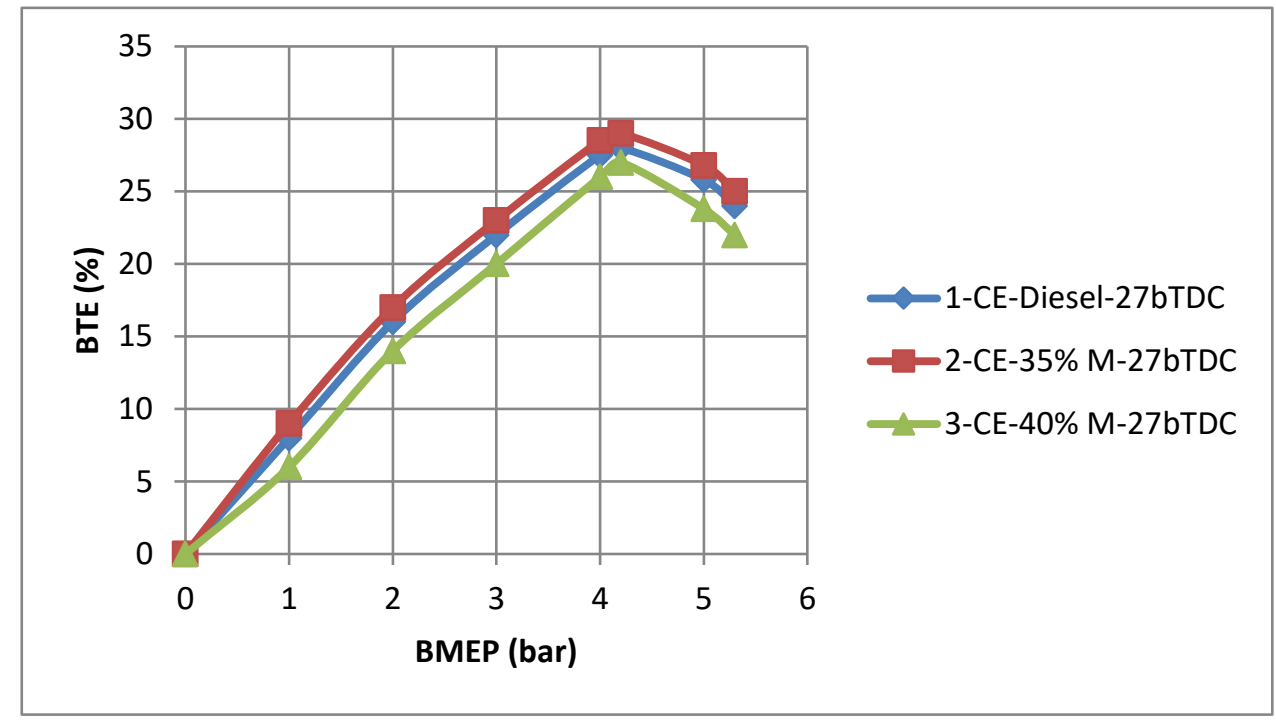

Figure 2. Variation of brake thermal efficiency (BTE) with BMEP in CE.

Figure 2 indicates that BTE increased at all loads with 35\% methanol (M) induction and with the increase of methanol induction beyond 35\%, it decreased at all loads in CE when compared with $\mathrm{CE}$ with diesel operation (standard diesel). The reason for improving the efficiency with the $35 \%$ methanol induction was because of improved homogeneity of the mixture with the presence of methanol, decreased dissociated losses, specific heat losses and cooling losses due to lower combustion temperatures. This was also due to high heat of evaporation of methanol, which caused the reduction the gas temperatures resulting in a lower ratio of specific heats leading to more efficient conversion of heat into work. Induction of 
methanol resulted in more moles of working gas, which caused high pressures in the cylinder. The observed increased in the ignition delay period would allow more time for fuel to vaporize before ignition started. This means higher burning rates resulted more heat release rate at constant volume, which was a more efficient conversion process of heat into work. Similar observations were made with butanol also.

Fig. 3 shows the variation of brake thermal efficiency with brake mean effective pressure of the engine in LHR engine with methanol induction. Curves from Figure 3 indicate that LHR engine showed an improvement in the performance with the carbureted methanol at all loads when compared to the standard diesel engine. This was due to recovery of heat from the hot insulated components of LHR engine due to high latent heat of evaporation of the methanol, which lead to increase in thermal efficiency. The maximum induction of methanol is $60 \%$ in LHR engine, which showed improvement in the performance at all loads when compared to standard diesel engine.

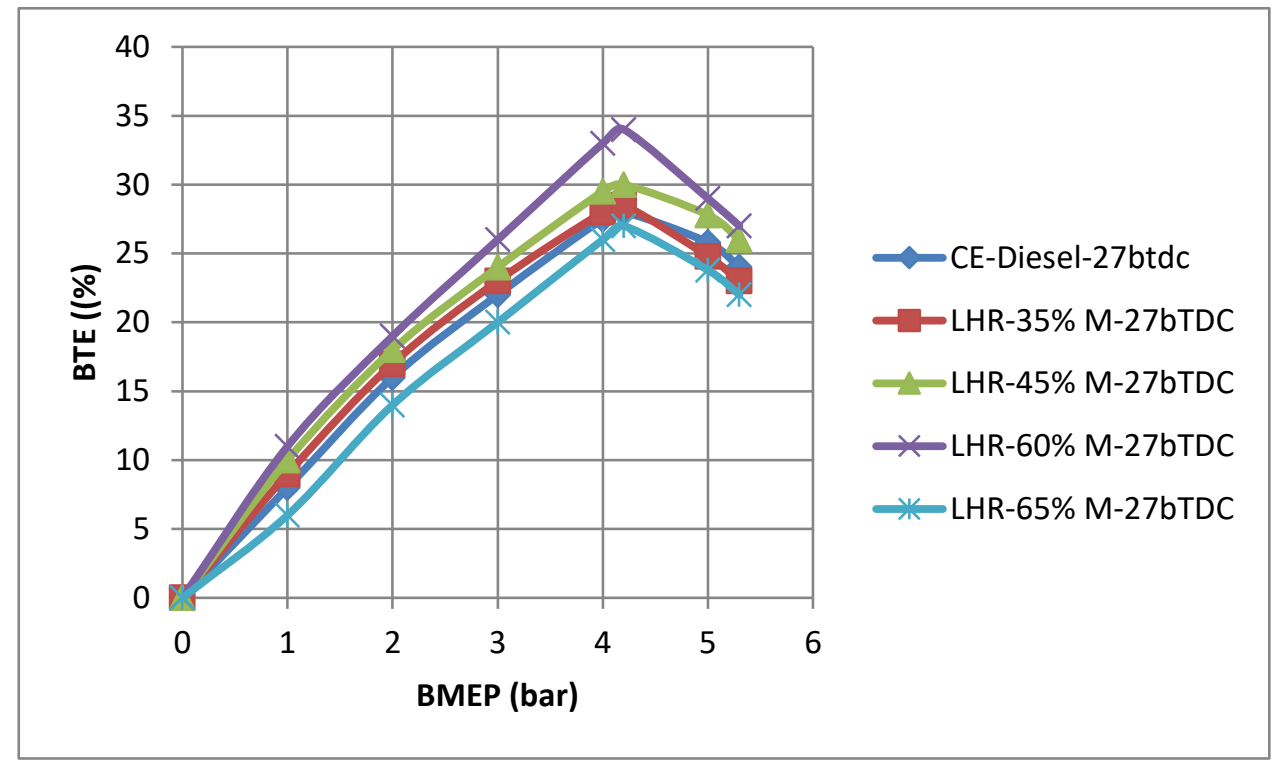

Figure 3. Variation of BTE with BMEP in LHR engine

However when the methanol induction was increased more than $60 \%$ in LHR engine, BTE is deteriorated at all loads when compared with standard diesel. This was due to increase of ignition delay. Butanol induction also followed similar trends in LHR engine. The maximum induction of butanol was found to be $60 \%$ in LHR engine.

\subsection{Exhaust Emissions}

Table 2 presents data of particulate matter at full load operation with induction of methanol and butanol with both versions of the engine. Particulate emissions were observed to be higher with LHR engine with pure diesel operation as it is noticed from Table. 2 in comparison with neat diesel operation on CE. This was due to fuel cracking at higher temperature, leading to increase in particulate matter. Higher temperature of LHR engine produced increased rates of both soot formation and burn up. The reduction in volumetric efficiency and air-fuel ratio were responsible factors for increasing particulate matter in the LHR engine near the peak load operation of the engine. As expected, particulate matter increased in the LHR engine because of higher temperatures and improper utilization of the fuel consequent upon predominant diffusion combustion. Particulate matter increased drastically with $\mathrm{CE}$ with crude cottonseed oil (CSO) in comparison with neat diesel operation on CE. High density, high duration of combustion due to high viscosity and high value of $\mathrm{C} / \mathrm{H}$ ratio in molecular composition of the 
CSO were the reason of higher particulate matter with crude CSO. However, LHR engine with vegetable oil operation reduced particulate levels in comparison with CE with CSO operation. Faster rate of combustion, reduction of ignition delay and increased heat release rate reduced particulate levels with LHR engine with cottonseed oil operation.

Particulate matter decreased with induction of alcohol. The combustion of injected fuel in case of pure vegetable oil operation was predominantly one of oxidation of products of destructive decomposition. In this case, there were greater chances of fuel cracking and forming carbon particles. This was due to high calorific value of the diesel causing high combustion temperatures leading to produced higher $\mathrm{NO}_{\mathrm{x}}$ levels $\mathrm{On}$ the other hand, the combustion of alcohol was predominantly a process of hydroxylation and the chances of fuel cracking were negligible.

Methanol does not contain carbon-carbon bonds and therefore cannot form any un-oxidized carbon particles or precursor to soot particles. One of the promising factor for reducing particulate matter with the alcohols was they contained oxygen in their composition which helped to reduce soot density. Soot emissions increased linearly with the increase of carbon to hydrogen atoms $(\mathrm{C} / \mathrm{H})$ ratio provided the equivalence ratio was not altered. This is because higher $\mathrm{C} / \mathrm{H}$ lead to more concentration of carbon dioxide, which would be further, reduced to carbon.

Table 2 Comparative data on particulate levels (Hartridge Smoke Unit) at full load operation

\begin{tabular}{|c|c|c|c|c|c|c|c|c|}
\hline \multirow{4}{*}{$\begin{array}{c}\text { Injection } \\
\text { timing } \\
\text { (bTDC) }\end{array}$} & \multirow{4}{*}{$\begin{array}{l}\text { Test Fuel/ } \\
\text { Engine } \\
\text { Version }\end{array}$} & \multirow{4}{*}{$\begin{array}{l}\text { Alcohol } \\
\text { induction } \\
\text { on mass } \\
\text { basis }\end{array}$} & \multicolumn{6}{|c|}{$\begin{array}{c}\text { Particulate levels at full load operation } \\
\text { (HSU) }\end{array}$} \\
\hline & & & \multirow{2}{*}{\multicolumn{3}{|c|}{$\begin{array}{l}\text { Methanol } \\
\text { njection pressure } \\
\text { (bar) }\end{array}$}} & \multicolumn{3}{|c|}{ Butanol } \\
\hline & & & & & & Inje & $\begin{aligned} & \text { tion } \text { p } \\
& \text { (bar }\end{aligned}$ & essure \\
\hline & & & 190 & 230 & 270 & 190 & 230 & 270 \\
\hline \multirow{7}{*}{27} & Diesel/CE & $0 \%$ & 48 & 40 & 34 & 48 & 40 & 34 \\
\hline & $\mathrm{CSO} / \mathrm{CE}$ & $0 \%$ & 65 & 63 & 58 & 65 & 63 & 58 \\
\hline & CSO/LHR & $0 \%$ & 45 & 40 & 35 & 45 & 40 & 35 \\
\hline & Diesel/LHR & $0 \%$ & 60 & 55 & 50 & 60 & 55 & 50 \\
\hline & \multirow{2}{*}{$\mathrm{CE}$} & $35 \%$ & 38 & 33 & 28 & 42 & 37 & 32 \\
\hline & & $40 \%$ & -- & -- & 25 & -- & -- & 30 \\
\hline & LHR & $60 \%$ & 25 & 20 & 15 & 30 & 25 & 20 \\
\hline
\end{tabular}

Consequently, induction of alcohol reduced the quantity of carbon particles in the exhaust gases as the values of $\mathrm{C} / \mathrm{H}$ for diesel fuel, vegetable oil, methanol and butanol are $0.45,0.83$, 0.25 and 0.4 respectively. Lower particulate emissions at full load were observed in both versions of the engine in dual fuel mode when compared with neat diesel operation on CE. LHR engine with $60 \%$ methanol induction showed lower particulate emissions, when compared with CE with 35\% methanol induction. Particulate levels decreased with the increase of methanol induction in both versions of the engine. In dual fuel operation, particulate matter further decreased with increase of injection pressure in both versions of the engine as it is noticed from the Table 2, due to efficient combustion at higher injection pressures, which improved the atomization hence faster rate of combustion and shorter combustion duration in both versions of the engine. Particulate levels were marginally lower with methanol operation in comparison with butanol operation in both versions of the engine as the value of $\mathrm{C} / \mathrm{H}$ ratio of methanol (0.25) is lower than butanol (0.4).

The temperature and availability of oxygen are the reasons for the formation of $\mathrm{NO}_{\mathrm{x}}$. Table. 3 shows data of nitrogen oxide $\left(\mathrm{NO}_{\mathrm{x}}\right)$ levels at full load operation with different versions of the engine with test fuels. LHR engine with diesel operation increased $\mathrm{NO}_{\mathrm{x}}$ levels drastically in comparison with $\mathrm{CE}$ with diesel operation. Improved heat release rate affected combustion 
temperatures and thus increased $\mathrm{NO}_{\mathrm{x}}$ levels with LHR engine with diesel operation. $\mathrm{CE}$ with crude vegetable oil operation reduced $\mathrm{NO}_{\mathrm{x}}$ levels when compared with $\mathrm{CE}$ with neat diesel operation. As the fuel, CSO is high viscous, duration of combustion is high leading to produce lower combustion temperatures and thus lower $\mathrm{NO}_{\mathrm{x}}$ levels.

From Table, it is noticed that $\mathrm{NO}_{\mathrm{x}}$ emissions decreased with the increase of percentage of alcohol induction in both versions of the engine, due to lower combustion temperatures with the absorption of combustion temperatures with their high latent heat of evaporation of alcohols. The low value of $\mathrm{C} / \mathrm{H}$ ratio in alcohols have indirect effect in reducing oxygen availability in the gases, which leads to the reduction of $\mathrm{NO}_{\mathrm{x}}$.

Table 3 Comparative data on $\mathrm{NO}_{\mathrm{x}}$ levels at full load operation

\begin{tabular}{|c|c|c|c|c|c|c|c|c|}
\hline \multirow{4}{*}{$\begin{array}{c}\text { Injection Timing } \\
\text { (bTDC) }\end{array}$} & \multirow{4}{*}{$\begin{array}{l}\text { Test Fuel/ } \\
\text { Engine } \\
\text { Version }\end{array}$} & \multirow{4}{*}{$\begin{array}{l}\text { Alcohol } \\
\text { induction } \\
\text { on mass } \\
\text { basis }\end{array}$} & \multicolumn{6}{|c|}{ NOx at peak load operation (ppm) } \\
\hline & & & \multicolumn{3}{|c|}{ Methanol } & \multirow{2}{*}{\multicolumn{3}{|c|}{$\begin{array}{c}\text { Butanol } \\
\begin{array}{c}\text { Injection pressure } \\
\text { (bar) }\end{array}\end{array}$}} \\
\hline & & & \multicolumn{3}{|c|}{ Injection pressure (bar) } & & & \\
\hline & & & 190 & 230 & 270 & 190 & 230 & 270 \\
\hline \multirow{7}{*}{27} & Diesel/CE & $0 \%$ & 850 & 900 & 950 & 850 & 900 & 950 \\
\hline & $\mathrm{CSO} / \mathrm{CE}$ & $0 \%$ & 675 & 725 & 775 & 675 & 725 & 775 \\
\hline & $\mathrm{CSO} / \mathrm{LHR}$ & $0 \%$ & 1270 & 1230 & 1180 & 1270 & 1230 & 1180 \\
\hline & Diesel/LHR & $0 \%$ & 1300 & 1250 & 1200 & 1300 & 1250 & 1200 \\
\hline & \multirow{3}{*}{$\begin{array}{l}\text { CE } \\
\text { LHI }\end{array}$} & $35 \%$ & 425 & 475 & 525 & 475 & 525 & 575 \\
\hline & & $40 \%$ & -- & -- & 475 & -- & -- & 525 \\
\hline & & $60 \%$ & 750 & 700 & 650 & 800 & 750 & 700 \\
\hline
\end{tabular}

However, LHR engine with different percentages of alcohol induction showed higher $\mathrm{NO}_{\mathrm{x}}$ levels compared with CE with $35 \%$ methanol induction, due to increase of gas temperatures in LHR engine. However, they decreased with increase of injection pressure in LHR engine and increased with $\mathrm{CE}$ with test fuels because of increase of combustion temperatures in CE, while decrease of the same in LHR engine, as noticed from Table 3. $\mathrm{NO}_{\mathrm{x}}$ levels were lower with methanol operation when compared with butanol operation on both versions of the engine. This was due to decrease of gas temperatures because of high latent heat of evaporation of methanol.

The aldehydes are responsible for pungent smell of the engine and affect the human beings when inhaled in the large quantities. The volatile aldehydes are eye and respiratory tract irritants. Though Government legislation has not been pronounced regarding the control of aldehyde emissions, when more and more alcohol engines are coming to existence severe measures the controlling of aldehydes emitted out through the exhaust of the alcohol run engines will have to be taken as serious view. It could be seen from the Table 4, that formaldehyde emissions were low with pure diesel operation in both CE and LHR engine.

Formaldehyde emissions increased drastically with methanol induction in both CE and LHR engine. With increased induction of methanol up to 60\%, CE registered very high value of formaldehyde emissions in the exhaust, which showed the significant reduction in LHR engine. Hot environment of LHR engine completed combustion reactions and reduced the emissions of intermediate compounds, aldehydes. Hence it is concluded that LHR engine was more suitable for alcohol engines in comparison with pure diesel operation. However, formaldehyde emissions decreased with LHR engine in comparison with CE with the same amount of alcohol induction. This showed that LHR engine improved combustion and intermediate compounds were not formed during the combustion. Formaldehyde emissions were higher with methanol operation when compared with ethanol operation on both versions of the engine.

Table 4 Comparative data on Formaldehyde emissions at peak load operation 


\begin{tabular}{|c|c|c|c|c|c|c|c|c|}
\hline \multirow{4}{*}{$\begin{array}{c}\text { Injection } \\
\text { timing } \\
\text { (bTDC) }\end{array}$} & \multirow{4}{*}{$\begin{array}{l}\text { Test Fuel/ } \\
\text { Engine Version }\end{array}$} & \multirow{4}{*}{$\begin{array}{l}\text { Alcohol } \\
\text { induction } \\
\text { on mass } \\
\text { basis }\end{array}$} & \multicolumn{6}{|c|}{$\begin{array}{c}\text { Formaldehyde emissions at peak load } \\
\text { operation ( } \% \text { concentration) }\end{array}$} \\
\hline & & & \multicolumn{3}{|c|}{ Methanol } & \multicolumn{3}{|c|}{ Butanol } \\
\hline & & & \multicolumn{3}{|c|}{ Injection pressure (bar) } & \multicolumn{3}{|c|}{$\begin{array}{l}\text { Injection pressure } \\
\text { (bar) }\end{array}$} \\
\hline & & & 190 & 230 & 270 & 190 & 230 & 270 \\
\hline \multirow{7}{*}{27} & Diesel/CE & $0 \%$ & 5.5 & 5.0 & 4.5 & 5.5 & 5.0 & 4.5 \\
\hline & $\overline{\mathrm{CSO} / \mathrm{CE}}$ & $0 \%$ & 12.5 & 11.2 & 9.5 & 12.5 & 11.2 & 9.5 \\
\hline & $\mathrm{CSO} / \mathrm{LHR}$ & $0 \%$ & 10.5 & 9.3 & 7.5 & 10.5 & 9.3 & 7.5 \\
\hline & Diesel/LHR & $0 \%$ & 8.0 & 7.5 & 7.0 & 8.0 & 7.5 & 7.0 \\
\hline & & $35 \%$ & 28.3 & 26.2 & 24.1 & 18.3 & 16.3 & 14.2 \\
\hline & $\mathrm{CE}$ & $40 \%$ & -- & -- & 26.4 & -- & -- & 16.4 \\
\hline & LHR & $60 \%$ & 30.2 & 28.2 & 26.6 & 24.3 & 22.1 & 20.4 \\
\hline
\end{tabular}

Table. 5 dhows the data of acetaldehyde emissions at full load with varied injection pressure with both versions of the engine with test fuels. Table 5 followed the similar trend with Table 4. LHR engine decreased acetaldehyde emissions in comparison with CE with the same amount of alcohol induction. This was due to improved combustion in LHR engine because of high evaporation rate with the hot environment provided with LHR engine leading to reduce fuel deposits. Acetaldehyde emissions increased with increase of injection pressure in both versions of the engine at various percentages of alcohol induction. From the Table, it is noticed that, acetaldehyde emissions were higher with butanol operation in comparison with methanol operation in both versions of the engine at various percentage induction of alcohol. This was due to presence of more number of carbon atoms. .

Table 5 Comparative data on Acetaldehyde emissions at peak load operation

\begin{tabular}{|c|c|c|c|c|c|c|c|c|}
\hline \multirow{4}{*}{$\begin{array}{c}\text { Injection } \\
\text { Timing } \\
\text { (bTDC) }\end{array}$} & \multirow{4}{*}{$\begin{array}{c}\text { Test Fuel/ } \\
\text { Engine Version }\end{array}$} & \multirow{4}{*}{\begin{tabular}{|c|} 
Alcohol \\
induction on \\
mass basis
\end{tabular}} & \multicolumn{6}{|c|}{$\begin{array}{c}\text { Acetaldehyde emissions at peak load operation } \\
(\% \text { concentration })\end{array}$} \\
\hline & & & \multicolumn{3}{|c|}{ Methanol } & \multicolumn{3}{|c|}{ Butanol } \\
\hline & & & \multicolumn{3}{|c|}{ Injection pressure (bar) } & \multicolumn{3}{|c|}{$\begin{array}{l}\text { Injection pressure } \\
\text { (bar) }\end{array}$} \\
\hline & & & 190 & 230 & 270 & 190 & 230 & 270 \\
\hline \multirow{7}{*}{27} & Diesel/CE & $0 \%$ & 7 & 6.5 & 6.0 & 7 & 6.5 & 6.0 \\
\hline & $\mathrm{CSO} / \mathrm{CE}$ & $0 \%$ & 9 & 8 & 6.9 & 9 & 8 & 6.9 \\
\hline & CSO/LHR & $0 \%$ & 8 & 7 & 5.7 & 8 & 7 & 5.7 \\
\hline & Diesel/LHR & $0 \%$ & 10 & 9.5 & 9.0 & 10 & 9.5 & 9.0 \\
\hline & & $35 \%$ & 18.3 & 16.4 & 14.7 & 28.3 & 26.5 & 24.5 \\
\hline & CE & $40 \%$ & -- & -- & 16.5 & -- & -- & 26.7 \\
\hline & LHR & $60 \%$ & 24.3 & 22.7 & 20.5 & 30.2 & 28.6 & 26.6 \\
\hline
\end{tabular}

\section{CONCLUSIONS}

The maximum induction of alcohol ( ethanol/butanol) was $35 \%$ with conventional engine, while it was $60 \%$ with LHR engine. Particulate levels at full load decreased by $34 \%, \mathrm{NO}_{\mathrm{x}}$ levels at peak load increased by $76 \%$, Aldehyde emissions decreased in LHR engine when compared with $\mathrm{CE}$ with methanol operation.

Butanol operation followed similar trends with methanol operation. However, methanol operation reduced pollutants more effectively than butanol operation on both versions of the engine. Increase of injection pressure decreased pollutants with test fuels. 


\section{ACKNOWLEDGMENTS}

Authors thank authorities of Chaitanya Bharathi Institute of Technology, Hyderabad for providing facilities for carrying out research work. Financial assistance provided by All India Council for Technical Education (AICTE), New Delhi, is greatly acknowledged.

\section{REFERENCES}

[1] Use of raw vegetable oil or animal fats in diesel engines. March, (2006). Engine Manufacturer's Association, Chicago.

[2] Cummins, C. Lyle, Jr. Diesel's Engine, Volume 1: From Conception To 1918. Wilsonville, OR, USA: Carnot Press, ISBN 978-0-917308-03-1,1993.

[3] Forson, F.K., Oduro, E.K. and Hammond-Donkoh, E. Performance of jatropha oil blends in a diesel engine. Renewable Energy, 29, 2004,1135-1145.

[4] Mahanta, P., Mishra, S.C. and Kushwash, Y.S. An experimental study of pongamia pinnata oil as a diesel substitute fuel. Proceedings IMechE., Journal of Power and Energy, 220, Part-A, 2006,803-808.

[5] Agarwal, D., Agarwal, A.K. Performance and emissions characteristics of jatropha oil (preheated and blends) in a direct injection compression ignition engine. Int. J. Applied Thermal Engineering, 27, 2007,2314-23.

[6] Hanbey Hazar and Huseyin Aydin. Performance and emission evaluation of a CI engine fueled with preheated raw rapeseed oil (RRO)-diesel blends. Applied Energy, 87, 2010,786-790.

[7] Misra, R.D., Murthy, M.S.Straight vegetable oils usage in a compression ignition engine-A review. Renewable and Sustainable Energy Reviews, 14, 2010,3005-3013.

[8] Jiwak Suryawanshi, Performance and emission characteristics of CI engine fueled by coconut oil methyl ester, SAE Paper No. 2006-32-0077.

[9] Murugesan, A., Umarani, C., Subramanian,R., Nedunchezhian, N. Bio-diesel as an alternate fuel for diesel engines. Renewable and Sustainable Energy Reviews, 13(3), 2009,653-662.

[10] Jindal, S., Nandwana, B.P., Rathore, N.S., Vashistha,V. Experimental investigation of the effect of compression ratio and injection pressure in a direct injection diesel engine running on Jatropha methyl ester. Applied Thermal Engineering, 30, 2010,442-448.

[11] Jaichandar, S. and Annamalai, K. The status of biodiesel as an alternative fuel for diesel engineAn Overview, Journal of Sustainable Energy \& Environment, 2, 2011,71-75

[12] Rasim, B. Performance and emission study of waste anchovy fish biodiesel in a diesel engine. Fuel Processing Technology, 92, 2011,1187-1194.

[13] Gupta, C.P. Use of alcohols in diesel engine. Transactions of Journal of Indian Institute of Engineers, 1983,199-212, ME-6.

[14] Samaga, B.S., Suresh Kumar, Y. and Venukumar, S. A dual fuel stratified charge combustion system. Proc. of VIII National Conference on I.C. Engines and Combustion, 1983,F30F37,Trivandrum.

[15] Haragopala Rao, B. Partial substitution of alcohols for diesel fuel", Proceedings of Workshop on Perspective of Alcohol Fuel Utilization in I.C. Engines, 1984,pp:33-38, Indian Institute of Petroleum, Dehradun.

[16] Venkanan, B.K., Gangavathi, P.B. and Swati, B.W. Alcohol fumigation close to the intake valve at increased injection pressure and with ignition improver enhances the performance and reduces emissions in a D.I. engine. Proc. of the XV National Conference on I.C. Engines and Combustion, 1997,144-150, Chennai. 
[17] Parlak, A., Yasar, H., ldogan O. The effect of thermal barrier coating on a turbocharged Diesel engine performance and exergy potential of the exhaust gas. Energy Conversion and Management, 46(3), 2005,489-499.

[18] Ekrem, B., Tahsin, E., Muhammet, C. Effects of thermal barrier coating on gas emissions and performance of a LHR engine with different injection timings and valve adjustments. Journal of Energy Conversion and Management, ISSN: 0196-890, 47,2006,1298-1310.

[19] Ciniviz, M., Hasimoglu, C., Sahin, F., Salman, M. S. Impact of thermal barrier coating application on the performance and emissions of a turbocharged diesel engine. Proceedings of The Institution of Mechanical Engineers Part D-Journal Of Automobile Engineering, 222 (D12), $2008,2447-2455$.

[20] Hanbey Hazar. Effects of bio-diesel on a low heat loss diesel engine. Renewable Energy, ISSN: 0960-1481, 34, 2009,1533-1537.

[21] Modi, A.J., Gosai, D.C. Experimental study on thermal barrier coated diesel engine performance with blends of diesel and palm bio-diesel. SAE International Journal of Fuels and Lubricants, 3(2), 2010, 246-259.

[22] Rajendra Prasath, B., P. Tamilporai ,P., Mohd.Shabir, F. Analysis of combustion, performance and emission characteristics of low heat rejection engine using biodiesel. International Journal of Thermal Science, 49, 2010, 2483-2490.

[23] MohamedMusthafa, M., Sivapirakasam, S.P. and Udayakumar.M. Comparative studies on fly ash coated low heat rejection diesel engine on performance and emission characteristics fueled by rice bran and pongamia methyl ester and their blend with diesel. Energy, 36(5), 2011.23432351.

[24] Parker, D.A. and Dennison, G.M. The development of an air gap insulated piston. SAE Paper No. 870652, 1987.

[25] Rama Mohan, K., Vara Prasad, C.M., Murali Krishna, M.V.S. Performance of a low heat rejection diesel engine with air gap insulated piston, ASME Journal of Engineering for Gas Turbines and Power, 121(3), 1999, 530-540.

[26] Ratna Reddy, T., Murali Krishna, M.V.S., Kesava Reddy, Ch. and Murthy, P.V.K. Performance evaluation of a medium grade low heat rejection diesel engine with mohr oil. International Journal of Recent Advances in Mechanical Engineering 1(1),May, 2012, 1-17.

[27] Chennakesava Reddy, Murali Krishna, M.V.S., Murthy, P.V.K., and Ratna Reddy,T. Potential of low heat rejection diesel engine with crude pongamia oil. International Journal of Modern Engineering Research,1(1), 2011,210-224.

[28] Janardhan, N., Murali Krishna, M.V.S., Ushasri, P. and Murthy, P.V.K. Potential of a medium low heat rejection diesel engine with crude jatropha oil. International Journal of Automotive Engineering and Technologies, 1(2), 2012,1-16

[29] Chowdary, R.P., Murali Krishna, M.V.S., Reddy, T.K.K. and Murthy,P.V.K. Performance evaluation of a high grade low heat rejection diesel engine with waste fried vegetable oil. International Journal of Scientific \& Technology, 2(3),March,2012,440-450

[30] Ratna Reddy, T., Murali Krishna, M.V.S., Kesava Reddy, Ch. and Murthy, P.V.K. Performance evaluation of a low heat rejection diesel engine with mohr oil based biodiesel. British Journal of Applied Science \& Technology 2(2), 2012, 179-198.

[31] Kesava Reddy, Ch., Murali Krishna, M.V.S., Murthy, P.V.K. and Ratna Reddy, T. Performance evaluation of a high grade low heat rejection diesel engine with crude pongamia oil. International Journal of Engineering Research and Applications, 2(5), 2012, 1505-1516.

[32] Murali Krishna, M.V.S., Vara Prasad, C.M. and Ramana Reddy, Ch. Control of aldehyde emissions in the diesel engines with alcoholic fuels. Indian Journal of Environmental Science \& Engineering, 48(1),2006, 61-64. 
[33] Murali Krishna, M.V.S. and Murthy, P.V.K. Studies on exhaust emissions from low heat rejection diesel engine with carbureted ethanol and jatropha oil. Ecology, Environment \&Conservation, 14 (2),2008, 263-268.

[34] Murali Krishna, M.V.S., Naga Sarada, S., Sudha Rani, G., Kalyani Radha, K. and Seshagiri Rao, V.V.R. A comparative study on exhaust emissions of a low heat rejection diesel engine with two different levels of insulation with carbureted methanol and crude pongamia oil. Pollution Research, 28(1), 2009, 93-96.

[35] Fulekar, M. H. Chemical pollution - a threat to human life, Indian Journal of Environmental Technology, 1, 1999, 353-359.

[36] Environmental Pollution Analysis, edited by Khopkar, S.M. [New Age International (P) Ltd, Publishers, New Delhi], 2004, 180-190.

[37] Engineering Chemistry, edited by Sharma, B.K. [Pragathi Prakashan (P) Ltd, Meerut], 2005, $150-160$. 